\title{
PEMBENTUKAN ELECTRONIC WORD OF MOUTH POSITIF MELALUI LAMAN INSTAGRAM (STUDI PADA KONSUMEN FATAHILLAH GINTING PHOTOGRAPHY)
}

\author{
Nufy Gera Rahmadany Sembiring ${ }^{1}$, Zuwina Miraza ${ }^{2}$ \\ ${ }^{1)}$ Program Studi Manajemen, Fakultas Ekonomi Bisnis, Universitas Harapan Medan \\ ${ }^{2 *}$ Program Studi Manajemen, Fakultas Ekonomi Bisnis, Universitas Harapan Medan
}

\begin{abstract}
The growth of internet users in Indonesia continues to increase. Hence, many companies ranging from micro, small, medium to large businesses, utilize Instagram in increasing their sales through electronic word of mouth processes. This study aims to determine the influence of perceived quality, experiential marketing on customer satisfaction and eWOM on Instagram. Population of this study are the clients who have used the services of Fatahillah Ginting Photography. The data collected from 170 respondents using questionnaire, and analyzed by path analysis technique. Some tests were conducted in this research are data quality test, classical assumption test, conformity test and path analysis. The Result shows that Perception of Quality and Experiential Marketing have direct influence on eWOM and indirectly through Consumer Satisfaction. Thus, in order to create positive eWOM on Instagram, Fatahillah Ginting Photography needs to increase customer loyalty by implementing experiential marketing concepts and providing high quality services.
\end{abstract}

Keywords: perceived quality, experiential marketing, electronic word of mouth, consumer satisfaction.

\section{PENDAHULUAN}

Pemasaran saat ini terus berkembang dan berubah dari konsep pemasaran konvensional menuju konsep pemasaran modern. Faktor - faktor seperti meningkatnya jumlah pesaing, kecanggihan teknologi, meningkatnya edukasi mengenai pemasaran semakin mempercepat dan memacu para pemasar untuk semakin kreatif memasarkan produknya. Dan salah satu hal yang saat ini harus dipikirkan oleh perusahaan untuk memenangkan persaingan adalah Internet. Tantangan utama bagi perusahaan saat ini adalah bagaimana mengelola, mengontrol, dan mengoptimalisasi potensi bisnis yang dipengaruhi oleh Internet (Reid $d k k$, 2006: 08). Pertumbuhan internet di Indonesia semakin pesat, Indonesia termasuk negara berkembang yang pertumbuhan internetnya tertinggi keempat di dunia. Menurut Survey APJII (Asosiasi Penyelenggara Jasa Internet Indonesia) jumlah pengguna Internet di Indonesia semakin meningkat tahun 2015 terdapat 110,2 juta, tahun 2016 mencapai 132,7 juta, dan pada tahun 2017 mencapai $143,26 \mathrm{jt}$ atau setara $54,68 \%$ terhadap populasi yang 262 juta jiwa penduduk Indonesia. Sekitar $70 \%$ pengguna internet merupakan pengguna aktif jejaring atau media sosial seperti Instagram, Facebook, Twitter, Path, Snapchat, Blog dan sisanya menggunakan internet untuk proses searching.

Media sosial adalah saluran atau sarana pergaulan sosial secara online di dunia maya. Para pengguna media sosial bisa dengan mudah berkomunikasi, berinteraksi, saling kirim pesan, dan saling berbagi (sharing), dan membangun jaringan (networking). Menurut Didit.com (26/2/18) Instagram menjadi media sosial yang sangat besar peningkatannya $25 \%$ dibandingkan media sosial lainnya dan sangat diminati saat ini. Instagram adalah sebuah aplikasi yang selalu menyajikan fitur-fitur baru untuk berbagi foto dan video yang memungkinkan penggunanya dapat mengambil foto, menerapkan filter digital untuk memberikan efek pada foto dan video, dan dapat membagikannya ke berbagai jejaring sosial lainnya yang digunakan sebagai tempat mengabadikan momen dan memperluas jaringan sosial, serta dapat menjadi media 
promosi untuk bisnis mereka. Maraknya pengguna media sosial Instagram ini dapat digunakan sebagai media electronic Mouth of Word (eWOM).

eWOM memiliki efek yang kuat dan besar karena berasal dari sumber yang terpercaya, pengaruhnya bahkan diakui lebih besar dari pengaruh iklan di televisi. Adapun variabelvariabel yang mempengaruhi terciptanya eWOM diantaranya ialah kualitas produk atau jasa, experiential marketing dan juga kepuasan konsumen.Ketiga variabel ini sangat penting dan menentukan sejauh mana keberhasilan eWOM yang diinginkan perusahaan. Seiring dengan besarnya jumlah pengguna media sosial Instagram Indonesia, membuka lebar peluang bisnis pemasar untuk menawarkan produk dan jasanya. Peluang ini salah satunya dimanfaatkan industri jasa dibidang fotografi yaitu jasa wedding photography.

Hal ini dikarenakan banyak masyarakat menginginkan suatu foto yang istimewa di momen paling bahagia yang diharapkan sekali seumur hidup. Fatahillah Ginting Photography merupakan sebuah startup local dengan jenis usaha jasa fotografi yang didirikan pada tahun 2015 di Medan. Jasa fotografi ini sudah aktif di media sosial Instagram sejak tahun 2015. Menurut observasi penulis, saat ini jumlah followers (pengikut) media sosial Instagram Fatahillah Ginting Photography (@fatahillahginting) terbanyak diantara jasa fotografi medan lainnya yang aktif di media sosial Instagram telah mencapai 29.800 dan memiliki $38,10 \%$ persantase followers (market share)menjadikannya market leader. Sebanyak $30 \%$ dari followersnya telah merekomendasikan jasa fotografi ini ke orang lain.

Semakin ketatnya persaingan dan munculnya pesaing baru telah mendorong Fatahillah Ginting Photography untuk mengoptimalisasi wadah yang ada berupa media sosial Instagram memilih untuk memaksimalisasi strategi pemasaran yang mana Instagram sebagai wadah yang paling sering digunakan target pasar. Dari sinilah penelitian ini dirancang untuk melihat sikap konsumen apakah dapat dibangun yang mana konsumen akan semakin mampu mempengaruhi konsumen lain dengan opini dan pengalaman mereka. Electronic Word of Mouth (eWOM) tercipta dengan baik jika kepuasan (Jan et all, 2013), kualitas (Satmoko dkk, 2016), dan experiential marketing (Zhang, 2010) yang dirasakan konsumen baik.

Berdasarkan permasalahan tersebut, maka penulis ingin meneliti dan menganalisa untuk mengetahui apakah terdapat pengaruh signifikan secara langsung maupun tidak langsung diantara variabel independen yaitu persepsi kualitas pelayanan dan experiential marketing terhadapelectronic word of mouth (eWOM) sebagai variabel dependen melalui kepuasan konsumen sebagai variabel intervening.

\section{TELAAH PUSTAKA DAN HIPOTESIS Kualitas Pelayanan}

Konsep kualitas dianggap sebagai ukuran kesempurnaan sebuah produk atau jasa yang terdiri dari kualitas desain dan kualitas kesesuaian (conformance quality). Maka kualitas pelayanan atau jasa (Tjiptono \& Chandra 2011) adalah sebagai ukuran seberapa bagus tingkat layanan yang diberikan mampu terwujud sesuai harapan pelanggan.Menurut Kotler (2012) mengemukakan bahwa kualitas adalah keseluruhan ciri serta sifat dari suatu produk atau pelayanan yang berpengaruh pada kemampuannya untuk memuaskan kebutuhan yang dinyatakan atau tersirat. Bila pelayanan yang mereka terima atau nikmati ternyata jauh dibawah dari apa yang mereka harapkan, konsumen akan kehilangan minat terhadap pemberian pelayanan atau jasa tersebut. Sebaliknya, jika jasa yang mereka nikmati memenuhi atau melebihi tingkat kepentingan mereka cenderung akan memakai produk pelayanan atau jasa tersebut.

Kualitas pelayanan berpengaruh langsung terhadap kepuasan konsumen (Satmoko, 2016). Evaluasi kualitas oleh pelanggan adalah hasil dari manfaat yang mereka dapatkan dengan menggunakan produk (layanan) dan citranya. Namun, masalah utama yang timbul dalam pengelolaan kualitas layanan di perusahaan jasa adalah, quality tidak dapat dengan mudah diidentifikasi dan diukur karena keistimewaan jasa. Oleh karena itu, persepsi kualitas layanan yang sesuai dengan harapan pelanggan merupakan hasil dari perbandingan antara harapan pelanggan terkait dengan layanan tertentu dan persepsi mereka tentang bagaimana layanan harus disediakan (Dukic 
\& Kijevkanin, 2016)

H1: Kualitas pelayanan berpengaruh positif dan signifikan terhadap kepuasan konsumen.

Satmoko dkk, 2016 menyatakan bahwa kualitas pelayanan berpengaruh terhadap WoM. Pelanggan akan memasarkan produk, jasa atau merek itu ke dalam daftar percakapan dan secara sadar atau tidak sadar mengungkapkan kepada orang lain secara lisan ataupun tulisan (electronic word of mouth) dalam berbagai kesempatan oleh karena itu membangun kualitas pelayanan secara maksimal dapat membangun WOM positif jika dikelola secara tepat.

$\mathrm{H} 2$ : Kualitas pelayanan berpengaruh positif dan signifikan terhadap eWOM

\section{Experiential Marketing}

Experiential marketing adalah suatu konsep pemasaran yang bertujuan untuk membentuk pelanggan - pelanggan yang loyal dengan menyentuh emosi mereka dan memberikan suatu perasaan yang positif terhadap produk dan jasa (Kartajaya, 2012). Experiential marketing merupakan sebuah metode komunikasi tatap muka,yang menimbulkan perasaan kepada pelanggannya secara fisik dan emosional sehingga pelanggan mengharapkan untuk menjadi relevan dan interaktif untuk beberapa merek dan merasakan juga mengalami sepenuh hati (Williams Jr., 2011).

Experential Marketing merupakan strategi atau cara untuk mengolah pengalaman konsumen saat menggunakan produk atau jasa yang ditawarkan. Ketika pelanggan memperoleh pengalaman positif yang unik serta berkesan dan pelanggan senang atas pengalaman yang diperolehnya menunjukan bahwa kinerja atas produk dan jasa yang diberikan sesuai bahkan melebihi harapan pelanggan yang artinya pelanggan puas atas produk atau jasa tersebut. Sense dan feel yang merupakan bagian dari experience marketing berpengaruh secara positif terhadap kepuasan konsumen media sosial di Malaysia (Alkiani, 2013)

H3: Experiential marketing berpengaruh positif dan signifikan terhadap kepuasan konsumen.

Sebagian besar konsumen dapat memberitahukan pengalamannya melalui internet dan mempengaruhi konsumen lainnya melalui Electronic Word of Mouth. Zhang
(2010), juga menyebutkan ketika terjadi pertukaran informasi melalui Electronic Word of Mouth konsumen akan melakukan evaluasi terhadap produk. Selain itu, Electronic Word of Mouth positif juga dapat mempersuasi pelanggan potensial dan mempengaruhi persepsi konsumen terhadap suatu review produk ataupun produk yang direkomendasikan pelanggan lain.

H4: Experiential marketing berpengaruh positif dan signifikan terhadap eWOM

\section{Kepuasan Konsumen}

Kepuasan konsumen menurut Kotler (2012) adalah perasaan senang atau kecewa seseorang yang muncul setelah membandingkan antara persepsi/kesannya terhadap kinerja (atau hasil) suatu produk dan harapan-harapannya. Perasaan senang atau kecewa seseorang yang muncul setelah membandingkan kinerja (hasil) produk yang dipikirkan terhadap kinerja yang diharapkan Tjiptono (2011). Dari pendapat diatas, dapat disimpulkan kepuasan konsumen merupakanrespon pelanggan terhadap ketidaksesuaian antara tingkat kepentingansebelumnya dan kinerja aktual yang dirasakannya setelah pemakaian.

Kepuasan pelanggan memberikan pengaruh yang kuat terhadap WOM (Jan et all, 2013). Sehingga jika kepuasan pelanggan tinggi maka percetakan tersebut memiliki potensi sumber pendapatan masa depan terutama bagi pembelian kembali, menekan biaya komunikasi pemasaran, dan penjualan, serta layanan pelanggan, menumbuhkan rekomendasi positif word of mouth serta dapat meningkatkan jaringan pemasok, mitra bisnis dan saluran distribusi, keadaan yang menguntungkan ini dapat memberikan kontribusi yang cukup besar bagi word of mouth.

H5: Kepuasan konsumen berpengaruh positif dan signifikan terhadap eWOM

H6: Kepuasan konsumen memediasi pengaruh kualitas pelayanan terhadap eWOM

H7: Kepuasan konsumen memediasi pengaruh experiential marketing terhadap Ewom

\section{Electonic Word of Mouth (eWOM)}

Menurut Hennig-Thurau

(2004),Electronic Word of Mouth (eWOM) merupakan bentuk komunikasi pemasaran yang berisi tentang pertukaran informasi dan 
pernyataan positif atau negatif yang dilakukan digunakan dalam penelitian ini adalah pelanggan potensial, pelanggan maupun kuesioner, yaitu metode pengumpulan data mantan pelanggan tentang suatu produk atau yang dilakukan dengan mengajukan lembaran perusahaan, yang tersedia bagi banyak orang angket yang berisi daftar pertanyaan kepada atau lembaga melalui media internet secara klien atau konsumen Fatahillah Ginting eletronik (tanpa komunikasi face to face). Photography yang menggunakan media sosial Informasi Word of Mouth yang tersedia secara Instagram mengenai kualitas pelayanan, online jauh lebih produktif dalam jumlah experiential marketing, kepuasan konsumen dibandingkan dengan informasi yang dan eWOM. Pengukuran variabel penelitian ini diperoleh dari kontak tradisional di dunia dilakukan dengan menggunakan kuesioner offline. Peneliti dapat dengan mudah secara personal. Adapun cara yang digunakan mengambil sejumlah besar pesan Electronic adalah dengan penyebaran data dikumpulkan Word of Mouth secara online dan dengan menggunakan angket tertutup dengan menganalisis karakteristik mereka seperti menggunakan Skala Likert.Populasi dalam jumlah kata sentimental yang digunakan, penelitian ini adalah yaitu sebesar 150 orang. posisi pesan, gaya pesan, dan sejenisnya. Maka jumlah sampel yang ditentukan dalam Secara keseluruhan, definisi operasional dan penelitian ini sebagai sampel sebanyak 107 pengukuran variable dapat dilihat pada Tabel orang. Penelitian ini juga termasuk penelitian 1.

Tabel 1. Definisi dan Pengukuran Variabel

\begin{tabular}{|c|c|c|}
\hline Variabel & Pengukuran Variabel & $\begin{array}{l}\text { Arah } \\
\text { Pengaruh }\end{array}$ \\
\hline $\begin{array}{l}\text { Kualitas } \\
\text { Pelayanan } \\
\text { (Tjiptono, } \\
\text { 2011) }\end{array}$ & $\begin{array}{l}\text { - Realibility } \\
\text { - Assurance } \\
\text { - Tangible } \\
\text { - Emphaty } \\
\text { - Responsivenes }\end{array}$ & $\begin{array}{l}\text { Positif } \\
(+)\end{array}$ \\
\hline $\begin{array}{l}\text { Experienti } \\
\text { al } \\
\text { Marketing } \\
\text { (Kartajaya } \\
\text {, 2012) }\end{array}$ & $\begin{array}{l}\text { - Sense } \\
\text { - Feel } \\
\text { - Act } \\
\text { - Think } \\
\text { - Relate }\end{array}$ & $\begin{array}{l}\text { Positif } \\
(+)\end{array}$ \\
\hline $\begin{array}{l}\text { Kepuasan } \\
\text { Konsumen } \\
\text { (Tjiptono, } \\
\text { 2012) }\end{array}$ & $\begin{array}{l}\text { - Overaall } \\
\text { satisfaction } \\
\text { - Confirmation of } \\
\text { xpectations } \\
\text { - Comparisonto ideal }\end{array}$ & $\begin{array}{l}\text { Positif } \\
(+)\end{array}$ \\
\hline $\begin{array}{l}\text { Electronic } \\
\text { Word of } \\
\text { Mouth } \\
\text { (Jalilvand, } \\
\text { 2012) }\end{array}$ & $\begin{array}{l}\text { - Platform assistance } \\
\text { - Venting negative } \\
\text { feelings } \\
\text { - Concern for other } \\
\text { consumers } \\
\text { - Concern for other } \\
\text { consumers } \\
\text { - Extraversion/positi } \\
\text { ve self- } \\
\text { enhancement } \\
\text { - Social benefits } \\
\text { - Economic } \\
\text { incentives } \\
\text { - Helping the } \\
\text { company } \\
\text { - Advice seeking }\end{array}$ & \\
\hline
\end{tabular}

kuantitatif dengan metode analisis jalur (analysis path) yang bertujuan untuk mengetahui hubungan antara dua variabel atau lebih dengan penelitian akan dapat dibangun suatu teori yang dapat berfungsi untuk menjelaskan, meramalkan dan mengontrol gejala (Rusiadi, 2013). Dibawah ini merupakan model jalur berdasarkan variabel yang terdapat dalam penelitian ini:

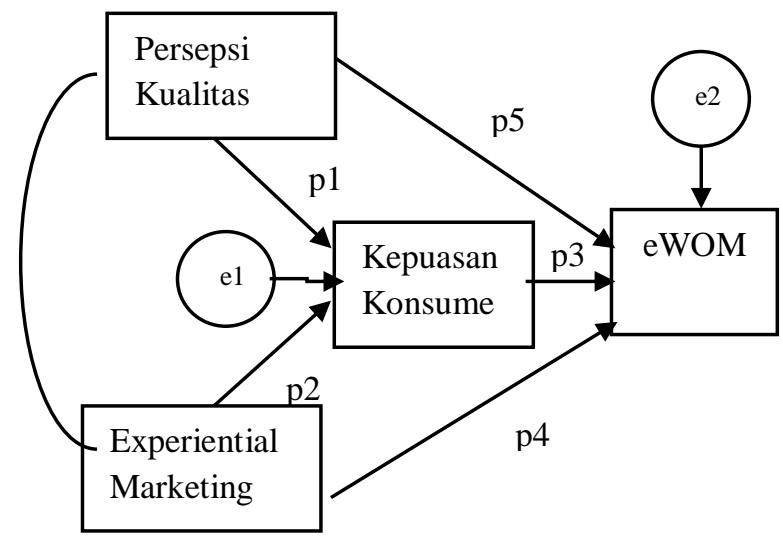

Gambar 1. Model Analisis Jalur Variabel

Persamaan strukturalnya adalah sebagai berikut:

Kepuasan Konsumen $=\beta 1$ Persepsi Kualitas + $\beta 2$ Experiential Marketing $+\varepsilon 1$

$\mathrm{eWOM}=\beta 1$ Persepsi Kualitas $+\beta 2$ Experiential Marketing $+\beta 3$ Kepuasan Konsumen $+\varepsilon 2$

Sumber data penelitian adalah data primer.Teknik pengumpulan data yang 
Total effect persepsi kualitas $=(\mathrm{p} 5)+(\mathrm{p} 1)(\mathrm{p} 3)$ Total effect experiential marketing $=(\mathrm{p} 4)+$

Total effect eWOM = (p3)

(p2)(p3)

\section{HASIL DAN PEMBAHASAN}

\section{Analisis Data}

Pengujian validitas data dalam penelitian ini menggunakan Correlated ItemItem Correlation. Analisis ini dilakukan dengan cara mengkorelasi masing-masing skor item dengan skor total dan melakukan korelasi terhadap nilai koefisien korelasi estimasi. Uji validitas dilakukan dengan membandingkan nilai $r$ hitung dengan $r$ table, $\mathrm{r}$ table untuk $\mathrm{n}=107$, maka $\mathrm{df}=\mathrm{n}-2=105$, taraf signifikan 5\% adalah 0,1900. Hasil penelitian menunjukkan bahwa semua item pernyataan dinyatakan valid dikarenakan rhitung lebih besar dibanding rtabel.

Hail uji reliabilitas menggunakan CronbachAlpa mengungkapkan bahwa, jika nilai alpha $>0,60$, maka dikatakan reliable. Hasil uji reliabilitas untuk variabel kualitas pelayanan 0,830 untuk variabel Experiential Marketingsebesar 0,826 untuk variabel Electronic Word of Mouth0,901 dan untuk variabek Kepuasan Konsumen adalah sebesar 0,862 . Semua variabel dinyatakan reliable, karena lebuh besar dari 0,60.

\section{Uji Asumsi}

Uji Normalitas

Klasik

Pembuktian apakah data tersebut memiliki distribusi normal atau tidak dapat dilihat pada bentuk distribusi datanya, Dapat digunakan dalam uji normalitas yaitu Analisis Statistik Kolmogorov-Simirnov (K-S). Uji K$\mathrm{S}$ dilakukan dengan menghitung residual data distribusi normal.

Tabel 1. Uji Normalitas

\begin{tabular}{lll}
\hline Model & $\begin{array}{l}\text { Asymp. Sig. (2- } \\
\text { tailed) }\end{array}$ & Keterangan \\
\hline Model 1 & ) .200 & Normal \\
Model 2 & J.054 & Normal \\
\hline
\end{tabular}

Berdasarkan tabel di atas, hasil pengujian normalitas data telah memenuhi asumsi normalitas dan berdistribusi secara normal, dimana asymp sig one sample kolmogorov smirnov test lebih besar 5\% $(0,05)$.

\section{Uji Multikolinearitas}

Tabel 2. Hasil Uji Multikolinieritas

$$
\begin{array}{lll}
\text { Variabel } & \text { Variance } & \text { Keterangan } \\
& \text { Inflation } & \\
& \text { Factor (VIF) }
\end{array}
$$

Model 1 Persepsi 1,786 Bebas multikolinearitas Kualitas

Experiental 1,786 Bebas multikolinearitas Marketing

Model 2 Persepsi 2,027 Bebas multikolinearitas Kualitas

Experiental 2,445 Bebas multikolinearitas Marketing

Kepuasan 2,428 Bebas multikolinearitas Konsumen

Sumber : Hasil Pengolahan SPSS versi 22.0

Tabel 2 menunjukkan VIF tidak yang ada lebih besar dari 10 artinya tidak terjadi multikolineritas antar variabel independen dalam model regresi.

\section{Uji Heterokedastisitas}

Pengujian

terhadap heteroskedastisitas dilakukan melalui uji Glejser, dengan meregresikan nilai absolut residual model, jika hasil pengujian tidak signifikan maka model tersebut mengandung unsur homoskedastisitas (tidak ada gejala multikolinieritas) demikian juga sebaliknya (Ghozali, 2013). Berikut disajikan hasil pengujian heteroskedastisitas melalui uji Glejser:

Sumber: Hasil Pengolahan SPSS versi 22.0 
Tabel 3. Hasil Uji Heterokedastisitas

\begin{tabular}{ccc}
\hline Variabel & $\begin{array}{c}\text { Variance } \\
\text { Inflation } \\
\text { Factor (VIF) }\end{array}$ & Keterangan \\
\hline Model $1 \begin{array}{c}\text { Persepsi } \\
\text { Kualitas } \\
\text { Experiental } \\
\text { Marketing }\end{array}$ & 0,335 & Bebas heteroskedastisitas \\
Model $2 \begin{array}{c}\text { Persepsi } \\
\text { Kualitas } \\
\text { Experiental } \\
\text { Marketing } \\
\text { Kepuasan } \\
\text { Konsumen }\end{array}$ & 0,240 & Bebas heteroskedastisitas \\
& 0,218 Bebas heteroskedastisitas \\
\end{tabular}

Sumber : Hasil Pengolahan SPSS versi 22.0

\section{Uji Kesesuaian}

Tabel 4. Hasil Uji Kesesuaian Model 1

\begin{tabular}{ccc}
\hline Variabel & Variance & Keterangan \\
& Inflation & \\
& Factor (VIF) & \\
\hline
\end{tabular}

Model 1 Persepsi 0,335 Bebas heteroskedastisitas Kualitas

Experiental 0,455 Bebas heteroskedastisitas Marketing

Model 2 Persepsi 0,103 Bebas heteroskedastisitas Kualitas

Experiental 0,240 Bebas heteroskedastisitas Marketing

Kepuasan 0,218 Bebas heteroskedastisitas Konsumen

Sumber : Hasil Pengolahan SPSS versi 22.0

Tabel4. Hasil Uji Kesesuaian Model 1

\begin{tabular}{llll}
\hline & $\begin{array}{l}\text { Instandardized } \\
\text { Coefficiens } \\
\text { Beta }\end{array}$ & Signifikansi & $\begin{array}{c}\text { Koefisien } \\
\text { Determinasi }\end{array}$ \\
\hline Persep & 0,336 & 0,000 & \\
Kualitas & & & \\
\hline
\end{tabular}

Experiental $0,494 \quad 0,000$
Marketing

R Square $\quad 0,588$

Berdasarkan table 4 di atas diketahui bahwa semua variabel pada model 1 signifikan pada $\square=5 \%$. Hal ini berarti bahwa ada pengaruh positif dan signifikan dari kualitas pelayanan terhadap kepuasan pelanggan, sehingga $\mathrm{Ha}$ diterima dan H0 ditolak. Jadi H1 yang menyatakan ada pengaruh persepsi kualitas pelayanan terhadap kepuasan konsumen diterima. Pengaruh variabel experiential marketingterhadap kepuasan konsumen dapat dibuktikan dengan signifikansi 0,000 dan koefisien korelasi 0,494 sehingga $\mathrm{H} 2$ yang menyatakan ada pengaruh experiential marketing terhadap kepuasan konsumen diterima.

Tabel 5. Hasil Uji Kesesuaian Model 2

\begin{tabular}{|c|c|c|}
\hline & $\begin{array}{l}\text { Instandardized } \\
\text { Coefficiens } \\
\text { Beta }\end{array}$ & $\begin{array}{r}\text { Signifikansi Koefisien } \\
\text { Determinasi }\end{array}$ \\
\hline $\begin{array}{l}\text { Persepsi } \\
\text { Kualitas }\end{array}$ & 0,516 & 0,004 \\
\hline $\begin{array}{l}\text { Experiental } \\
\text { Marketing }\end{array}$ & al 1,018 & 0,000 \\
\hline $\begin{array}{l}\text { Kepuasan } \\
\text { Konsumen } \\
\end{array}$ & $\begin{array}{l}0,014 \\
\end{array}$ & 0,936 \\
\hline R Square & & 0,601 \\
\hline
\end{tabular}

Table 5 memperlihatkan hasil pengujian regresi model 2. Dalam hal ini, persepsi kualitas berpengaruh terhadap eWOM secara positif dan signifikan, dengan nilai signifikansi 0,004 dan koefisien korelasi 0,516 dan Experiential marketingberpengaruh positif dan signifikan dengan nilai koefisien 1,018 dengan signifikansi 0,000 . Sementara variabel kepuasan konsumen berpengaruh positif dan tidak signifikan terhadap eWOM, dengan nilai signifikansi 0,936 dan nilai koefisien korelasi sebesar 0,014, artinya variabel kepuasan konsumen tidak berpengaruh terhadap eWOM karena nilai signifikansi $>0,05$.

Berdasarkan output di atas diketahui nilai $\mathrm{R}$ Square $(R)^{2}$ model 1 sebesar 0,588 atau $58,8 \%$ dan model 2 sebesar 0,601 atau $60,1 \%$ yang menunjukkan bahwa perubahan variabel kualitas, experiential marketing dan kepuasan konsumen dapat menjelaskan variabel eWOM sedangkan sisanya dijelaskan oleh faktor faktor lain diluar model.

\section{Analisis Jalur (Path Analysis)}


Analisis jalur merupakan perluasan dari analisis regresi berganda untuk menaksir hubungan kausalitas antar variabel yang telah ditetapkan sebelumnya.Berdasarkan pada tabel 5, diketahui bahwa Unstandarized Coefficients Beta pada kualitas sebesar 0,516 dan kepuasan konsumen sebesar 0,014 dengan nilai $\mathrm{R}$ square yang terdapat pada tabel 6 adalah sebesar 0,601 yang menunjukkan bahwa sumbangan pengaruh X1 dan Z terhadap Y adalah sebesar 60,1\% Untuk mencari nilai e1dapat dicari dengan rumus $\mathrm{e} 1=\sqrt{(1-0,516)}=0,484$. Dengan demikian persamaan I : Y = 0,516 X1+0,014 Z+ 0,484 e1

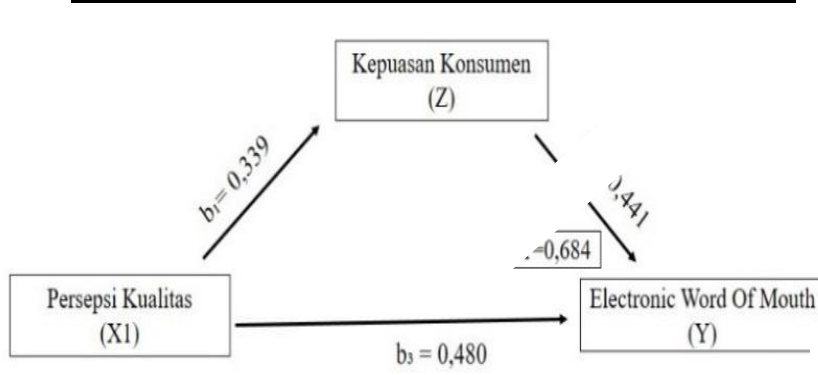

Gambar 4. Analisis Jalur Model 1

Untuk mengetahui apakah ada pengaruh signifikan memediasi variabel kepuasan pada pengaruh variabel kualitas terhadap electronic word of mouth maka digunakan rumus model Sobel Test. Dimana :

$P 2$ :koefisien pengaruh langsung kualitas terhadap electronic word of mouth

$P 3:$ total koefisien koefisien jalur kualitas terhadap electronic word of mouth

Sp2 :Standardized Coefficients Std. Error variabel independen

Sp3 :Standardized Coefficients Std. Error variabel dependen

\section{$\operatorname{Sp} 2 p 3$}

$$
=\sqrt{p 3^{2} S p 2^{2}+p 2^{2} S p 3^{2}+S p 2^{2}} S p 3^{2}
$$

variabel dependen, maka perlu menghitung nilai t dari koefisien $p 2 p 3$ :

$$
\boldsymbol{t}=\frac{\boldsymbol{p 2 p 3}}{\boldsymbol{S p 2 p 3}}=\frac{0,516 \times 0,014}{0,09696}=\mathbf{0 , 0 7 4 5}
$$

Nilai t-hitung $0,0745<1,983 \mathrm{t}$-tabel dengan tingakat signifikasi 0,05 sehingga secara signifikan tidak ada pengaruh tidak langsung dari kualitas terhadap electronic word of mouth.

Berdasarkan pada tabel 5, diketahui bahwa Unstandarized Coefficients Beta pada experiential marketing sebesar 1,018 dan kepuasan konsumen sebesar 0,014 dengan nilai $\mathrm{R}$ square yang terdapat pada tabel 6 adalah sebesar 0,601 yang menunjukkan bahwa sumbangan pengaruh $\mathrm{X} 1$ dan $\mathrm{Z}$ terhadap $\mathrm{Y}$ adalah sebesar $60,1 \%$ Untuk mencari nilai e2 dapat dicari dengan rumus $\mathrm{e} 2=\sqrt{(1-1018)}=-0,018$

$$
\text { Untuی persamaan II : } \mathbf{Y}=
$$

\section{1,018X2+0,014. $\quad 0,018$ e2}

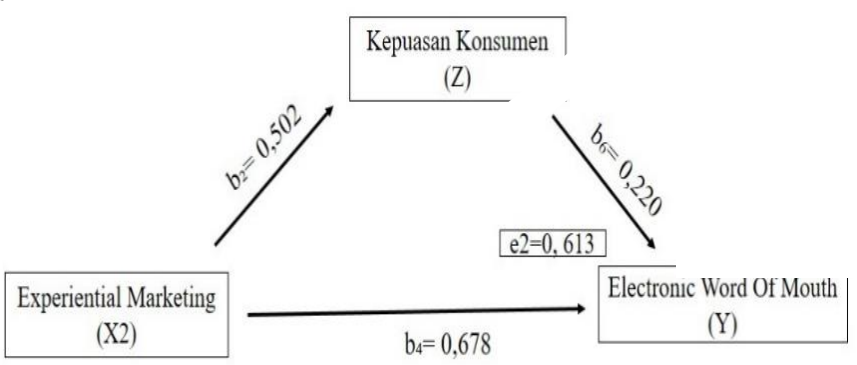

Gambar 5.Analisis Jalur Model 2

$$
\begin{aligned}
& S p 2 p 3 \\
& =\sqrt{p 3^{2} S p 2^{2}+p 2^{2} S p 3^{2}+S p 2^{2}} S p 3^{2} \\
& =\sqrt{(0,014)^{2}(0,169)^{2}+(1,018)^{2} \cdot(0,178)^{2}+(0,169)} \\
& =0,5734
\end{aligned}
$$

Untuk menguji signifikasi pegaruh tidak langsung variabel independen terhadap variabel dependen, maka perlu menghitung nilai t dari koefisien $p 2 p 3$ :

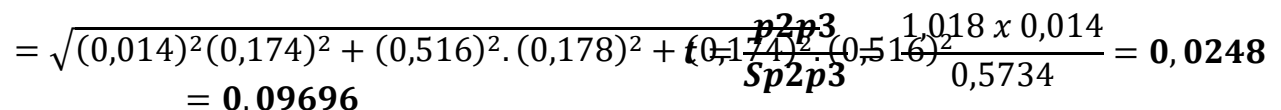

Untuk menguji signifikasi pegaruh tidak langsung variabel independen terhadap
Nilai t-hitung $0,0248<1,983$ t-tabel dengan tingakat signifikasi 0,05 sehingga secara signifikan tidak ada pengaruh tidak 
langsung dari experiential marketing terhadap electronic word of mouth.

Berdasarkan hasil uji sobel test di atas menyatakan bahwa variabel kepuasan kerja tidak terbukti sebagai variabel mediasi untuk menghubungkan variabel kualitas dan experiential marketing terhadap electronic word of mouth. Pernyataan ini diperkuat dengan nilai t hitung dari pengujian sobel test lebih kecil dari $\mathrm{t}$ tabel, artinya variabel independen dapat mempengaruhi variabel dependen secara langsung tanpa harus melalui variabel mediasi.

\section{KESIMPULAN DAN SARAN}

Berdasarkan hasil penelitian yang telah dilakukan tentang dampak presepsi kualitas dan experiential marketing terhadap electronic word of mouth melalui media sosial instagram dengan kepuasan konsumen sebagai variabel intervening (studi pada Fatahillah Ginting Photography)didapatkan hasil pengujian kualitas pelayanan dan experiential marketingberpengaruh signifikan dan positif terhadap kepuasan konsumen dan pengaruh tidak langsung pengujian kualitas pelayanan dan experiential marketingberpengaruh signifikan dan positif terhadap eWOM, itu artinya eWOM mampu menjadi mediasi yang baik bagi kualitas pelayanan dan experiential marketing dalam menciptakan kepercayaan konsumen untuk memakai jasa. Hal ini berarti semakin tinggi tingkat kualitas pelayanan dan experiential marketingyang diberikan Fatahillah Ginting Photography maka akan meningkatkan kepuasan pelanggan yang secara tidak langsung juga meningkatkan loyalitas pelanggan.

$$
\text { Bagi Fatahillah Ginting }
$$

Photography untuk mempertahankan dan meningkatkan kualitas jasa nya maka harus memberikan pelayanan yang cepat dan tepat, kemampuan dalam menanggapi keluhan pelanggan serta mampu mengatasi masalah yang dihadapi konsumen. Hal ini dilakukan agar konsumen merasa dihargai dan mendapakan pelayanan yang baik yang akan berdampak pada kepuasan konsumen yang menjadi pelanggannya tetap terjaga sehingga loyalitas mereka tetap tinggi dan mampu memberikan kesan yang baik dan positif untuk terciptanya electronic word of mouth di media sosial instagram Fatahillah Ginting
Photography. Dan untuk penelitian selanjutnya bisa dicoba dengan variabel intervening lainnya yang dapat memiliki pengaruh mediasi lebih besar.

\section{DAFTAR PUSTAKA \\ Buku Teks}

Adrian, Payne. (2000). Pemasaran Jasa. The Essecnce of Service Marketing. Yogyakarta: Andi.

Kotler, P. \& Armstrong, G. (2012). PrinsipPrinsip Pemasaran. Edisi 13. Jilid 1. Jakarta: Erlangga

Rusiadi, et al (2013). Metodologi Penelitian. Penelitian Kuantitatif. Bandung: Alfabeta.

Tjiptono \&Chandra. (2012). Strategi pemasaran. Kepuasan Pelanggan. Malang. Bayu media Publishing

Kartajaya. (2012). Konsep dan Strategi Pemasaran. Experiential Marketing. Edisi 4.Jakarta : Salemba Empat

\section{Jurnal Ilmiah}

Dukic \& Kijevkanin (2016). The Impact of Experiential Marketing on Customers Experential Value and Satisfaction. Journal of Business and Management. Jerman: Ludwig Maximilian University of Munich.

Harsasi, Meirani. (2006). Word Of Mouth(WOM) Dalam Industri Jasa : Kaitannya Dengan Sikap Dan Kemungkinan Membeli. Jurnal Bisnis Strategi. Vol. 15 No. 1 Juli 2006, 31-41.

Hennig-Thurau, T., Gwinner, K.P., Walsh, G. dan Gremler, D. D. (2012). Electronic Word-of-Mouth Via Customer-Opinion Platforms: What Motivates Consumer to Articulate Themselves on the Internet.Journal of Interactive Marketing, Vol 18/No 1, 38-52.

Jalilvand, M., R., dan Samiei, N. (2012). The Effect of E-WOM on Brand Image and Purchase Intention. Journal of Marketing Intelligence and Planning, Vol 30/No 4, 460-476.

Jan, Muhammad Tahir; Khaltom Abdullah; Ali Shafiq (2013). The Impact of Customer Satisfaction on Word of Mouth: Conventional Banks of Malaysia Investigated. International Journal of Information and Technology and Computer Science, Vol 10/No 3, 14-23.

Satmoko, Taufiq Dwi; Djoko Handojo dan Ngatno (2016). Pengaruh Kualitas 
Pelayanan Terhadap Word of Mouth, Melalui Kepercayaan dan Kepuasan Konsumen Sebagai Variabel Intervening Pada Star Clean Car Wash Semarang. Jurnal Ilmu Administrasi Bisnis, Vol 5/No 1.

Zhang, Jason Q; Georgiana Craciun; Dongwo Shin. (2010). When Does Electronic Word-of-mouth Matter? A Study of Consumer Product Reviews. Journal of Business Research, December 2010.

\section{Media cetak Online}

Kiani, G Reza. (2008). Marketing Opportunity in The Digital World. Henly Management College Oxfoeshire. $U K$. Internet Research Electronic Markerting Policy. (www. emearldsight.com) diakses tanggal 4 Februari 2018.

Schmitt, Bernd. (2010).Experiential Marketing: how to Get Costumer to Sense, Feel, Think, Act, and Relate to Your Company and Brands. New York: The Free Press.hal.22.

\section{Sumber online}

APJII. (2017). Infografis Penetrasi \&

Perilaku Pengguna Internet Indonesia 2017. http://www.apjii.com/surveyapjii/2017. htmldiakses 20 Februari, 2018

Didit.(2018). Instagram essential facts every marketer should know. https://www.didit.com/instagram-factsyou-should-know/diakses20 Februari, 2018

Reid et al.(2006). B2B International Internet Marketing : It Benchmarking Exercise. Wolverhampton Business School. UK (www.emeraldinsight.com/1463-

5771.htm)diakses 28 Februari, 2017. 